\title{
Unified Modeling Language
}

National Cancer Institute

\section{Source}

National Cancer Institute. Unified Modeling Language. NCI Thesaurus. Code C54193.

A non-proprietary, third generation modelling language. The Unified Modeling Language

is an open method used to specify, visualise, construct and document the artifacts of an

object-oriented software-intensive system under development. The UML represents a compilation of "best eng ineering practices" which have proven successful in modelling large, complex systems. 